\title{
PERINATAL MORTALITY AT KATHMANDU MODEL HOSPITAL
}

Shrestha S. R. ${ }^{1}$
Rajbhandari S. ${ }^{2}$

\section{ABSTRACT:}

Total number of 410 deliveries were performed at Kathmandu Model Hospital (KMH) during 33 months (April 96 -Dec 98 ). Among 410 deliveries 107 (26.09\%) cases were done by Lower Segment Caesarean Section (LSCS), 54 cases (13.37\%) by forceps delivery, $188(45.85 \%)$ cases normal vaginal delivery with epigiotomy and $61(14.87 \%)$ normal vaginal delivery with or without tear.

During this period, 6 twin delivery cases were observed. There were 14 cases of perinatal deaths (still birth $\mathbf{- 1 0}$ and neonatal-death - 4). Hence, perinatal mortality rate during this peroid in this hospital was 34.15.

Perinatal mortality was mostly due to severe prematurity, birth asphyxia, ante-partum haemorrhage (APH), intrauterine growth retardation (IUGR), congenital abnormalities and sepsis.

\section{KEY WORDS: Neonatal death, Still birth, Perinatal mortality, Antepartum haemorrhage (APH), Sepsis.}

\section{INTRODUCTION :}

Perinatal mortality is a big problem in developing countries. Every year about 140 million live babies born worldwide. Out of 10 babies, 9 born in developing countries. Eight million babies, mostly in developing countries die within first year of life and $50 \%$ of them die within first month life. ${ }^{1}$

In Asia PNMR is 53/1000 births. ${ }^{1}$ In nation wide, PNMR of Sri-Lanka is $25 / 1000$ births, Pakistan is $70 / 1000$ births, Thailand is 20/1000 births, Bang

1. MD, DCH, Department of Paediatrics, Patan Hospital

2. MBBS, MCPS, MPH,

Address for correspondence : $\quad$ Dr. Sita Ram Shrestha, MD, DCH, Department of Paediatrics Patan Hospital, GPO Box: 252, Kathmandu, Nepal.

Tel.: 522266 (Off.), Fax: 977-1-225559, email: patan@ hospital.wlink.com.np 
ladesh is $80 / 1000$ births, India is $65 / 1000$ births, Japan is $5 / 1000$ births and Nepal is $75 / 1000$ births. $^{2}$ In Africa this rate is $75 / 1000$ births in comparison to $39 / 1000$ in Latin America. This rate is very low in Europe (13/1000) and America (9/1000). ${ }^{1}$

In Nepal, out of every 1000 babies born, seven die in the first day of life, 16 die by the end of first week and about 30 die within first month of life. ${ }^{3}$

Perinatal period extends from 28th week of gestation to the first week of life.

Perinatal death includes still birth plus death of early neonate. The perinatal mortality rate (PNMR) is defined as the ratio of still birth plus early neonatal death divided by the total births per thousand births in a year. ${ }^{4,5}$

PNMR $=\underline{\text { Still births plus yearly neonatal deaths } \mathrm{x} 1000}$ Total births

PNMR is also calculated as:

Still births + Early Neonatal deaths weighing $>1000$ gms at birth $\times 1000$

Total birth weighing more than 1000 gms

More than $90 \%$ of neonatal death occur in first seven days and $40 \%$ of deaths of under five years of age occur in first 24 hours of life. ${ }^{6,7}$ Perinatal deaths are influenced by perinatal conditions and circumstances surroundings labour and delivery.

There is no record on still birth in Nepal. But the problem is very high. According to our study, still birth is high $(60 \%)$ in comparison to post-natal death $(40 \%)$.

\section{METHODS AND MATERIALS:}

This study was done at Kathmandu Model Hospital $(\mathrm{KMH})$, which is running under a non governmental organization known as Public Health Concern Trust (phect-Nepal), established in 1991.
$\mathrm{KMH}$ is a 55 bedded hospital with 10 maternity beds, 2 delivery tables, a neonate unit with 1 incubator. Most women, who are on regular Ante Natal Check up (ANC) in this hospital get admission through out patient department or emergency department for delivery. However, we do admit women, who have had ANC out side or without any ANC.

During admission, detail history regarding age, parity, obstretic history and other health status are taken. Regular check up are done by obstretician. Partograph is strictly maintained during labour. Deliveries are conducted by doctors (obstreticians) with the help of nurses on duty. All deliveries are attended by paediatrician and all new born babies are examined thoroughly during delivery and regular ward visit. New born babies are checked for maturity, congenital abnormalities etc. Weight of all new new born babies are taken and analyzed in relation to WHO weight standard for neonates of developing countries. With this we provide level II perinatal care in this hospital.

\section{RESULTS:}

Table 1

\begin{tabular}{lc}
\hline Total birth & 410 \\
\hline Total live births & 407 \\
\hline Total still birth & 9 \\
\hline Total neonatal death & 5 \\
\hline Total perinatal death & 14 \\
\hline
\end{tabular}

Table 1 shows total no. of birth, live birth during 33 months. Besides, this table also shows cases of still birth, neonatal death and perinatal death during the same period.

Table 2

Obstretic History of pregnant Women.

\begin{tabular}{cc|c|c|}
\hline \multicolumn{4}{c|}{ Parity } \\
\hline Year & primi & $\mathbf{2 - 4}$ & $>\mathbf{5}$ \\
\hline 1996 & 48 & 45 & 1 \\
\hline 1997 & 96 & 72 & 4 \\
\hline 1998 & 61 & 80 & 3 \\
Total & $\mathbf{2 0 5}(\mathbf{5 0 \%})$ & $\mathbf{1 9 7}(\mathbf{4 8 \%})$ & $\mathbf{8 ( 2 \% )}$ \\
\hline
\end{tabular}


This table shows, most of the deliveries occured in primigravida (50\%). Deliveries among multigravida is $48 \%$ and deliveries among grand multigravida is only $2 \%$.

Table 3

Age of Mother

\begin{tabular}{|c|cc|c|c|}
\multicolumn{5}{|c|}{ Age group } \\
Year & $15-19$ & $20-24$ & $25-29$ & $>30$ \\
\hline 1996 & 13 & 49 & 27 & 5 \\
\hline 1997 & 37 & 80 & 41 & 14 \\
1998 & 10 & 62 & 51 & 21 \\
\hline Total & $60(14.63 \%)$ & $191(46.58 \%)$ & $119(29.02 \%)$ & $40(9.75 \%)$
\end{tabular}

This table shows maximum number of deliveries occured among 20 - 24 years age group i. e. 119 (46.58\%). Average age of expectant mother during 33 months showed 23 yrs. Average age of primigravida mother is $21 \mathrm{yrs}$.

\section{Table 4}

\section{Average delivery per month}

\begin{tabular}{ll|l|llll|lll} 
Year Jan Feb & Mar & Apr & May & Jun Jul & Aug & Sep & Oct & Nov & Dec
\end{tabular}

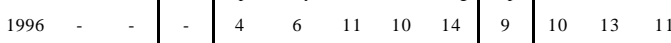

\begin{tabular}{lll|l|lllll|l|lll}
1997 & 17 & 9 & 13 & 12 & 10 & 5 & 16 & 12 & 20 & 24 & 13 & 14
\end{tabular}

\begin{tabular}{lll|l|lllll|l|lll}
1998 & 13 & 12 & 14 & 3 & 12 & 13 & 12 & 11 & 14 & 10 & 11 & 19
\end{tabular}

This table shows that maternity and neonatal unit was started in April 1996 and maximum no of deliveries occured in the month of October 1997.

Table 5

Weight of the baby

\begin{tabular}{cc|}
\hline $1000-1449$ gms & $7(1.70 \%)$ \\
$1500-2499$ & $51(12.25 \%)$ \\
\hline 2500 and above & $358(86.05 \%)$ \\
Total & $416(100 \%)$ \\
\hline
\end{tabular}

The above table shows that most of the babies born in this hospital has weight $>2.5 \mathrm{~kg}$, but average weight for male and female babies during this period corresponds to $2.85 \mathrm{~kg}$.
Table 6

Sex of the child.

\begin{tabular}{ccc|c|c|}
\hline Sex & $\mathbf{1 9 9 6}$ & $\mathbf{1 9 9 7}$ & $\mathbf{1 9 9 8}$ & Total \\
\hline Male & 50 & 83 & 82 & $215(51.7 \%)$ \\
\hline Female & 44 & 94 & 63 & $201(48.3 \%)$ \\
Total & 94 & 177 & 145 & $416(100 \%)$ \\
\hline
\end{tabular}

The above table shows that number of deliveries of male child is slight more than that of female child.

Table 7

Gestational age of the baby.

\begin{tabular}{l|cc|}
\hline \multicolumn{1}{c|}{ Maturity } & Number & $\%$ \\
Preterm $<37$ weeks & 31 & $7.4 \%$ \\
\hline Term & 361 & $86.8 \%$ \\
\hline Post term & 24 & $5.8 \%$ \\
\hline Total & 416 & $100 \%$ \\
\hline
\end{tabular}

This table shows that $86.77 \%$ of the babies delivered in KMH were term babies. Birth of pre-term and post-term babies are very low in comparision to term babies.

Table 8

Causes of Still birth.

\begin{tabular}{l|l|}
$\begin{array}{l}\text { Severe prematurity and congenital } \\
\text { abnormality }\end{array}$ & $\begin{array}{l}2 \text { (N.D.with } \\
\text { Epigiotomy) }\end{array}$ \\
\hline $\begin{array}{l}\text { Obustructed labour and hand prolapse } \\
\text { Injury (Fall from height } 2 \text { weeks prior } \\
\text { to delivery) }\end{array}$ & $\begin{array}{l}1 \text { (Ceasarean Section) } \\
1 \text { (N.D) }\end{array}$ \\
\hline $\begin{array}{l}\text { Fetal distress } \\
\text { APH (P.V.bleeding } 3 \text { times in toilet } \\
\text { before birth ) }\end{array}$ & 2 (N.D) \\
$\begin{array}{l}\text { Unknown causes (Loss of fetal } \\
\text { movement 20 days before birth }\end{array}$ & 2 (N.D) \\
\hline
\end{tabular}

Two of the major causes of still birth are severe prematurity and birth asphyxia. 
Table 9

Causes of early neonatal death

\begin{tabular}{l|c}
\hline \multicolumn{1}{c|}{ No Causes } & No. of cases \\
\hline Severe birth asphyxia & 2 \\
Severe prematurity & 1 \\
\hline Severe prematurity with & 1 \\
congenital abnormalities & \\
Sepsis & 1 \\
\hline
\end{tabular}

Severe birth asphyxia is the major cause leading to early neonatal death.

\section{DISCUSSION:}

The current status of maternal and child health are dismal in most developing countries including Nepal. Most deliveries are non institutional and only $6 \%$ of total births are attended by the trained man power. Over $90 \%$ of deliveries take place in rural areas, with problems of accessibility and acceptability of available health services. ${ }^{8}$

The Nepal Family Health Survey (NFHS) of 1996 indicates that $92 \%$ of all deliveries are conducted at home with $23 \%$ of the total deliveries attended by a traditional birth attendant (TBA), $9 \%$ by doctor or nurse, and $58 \%$ by a relative or neighbour or friend.

The inadequacy of perinatal service is reflected in the form of high incidence of low birth weight (25$30 \%$ ) and prevailing neonatal mortality rate of over 50 per thousand live births. ${ }^{8}$

In our study, PNMR of KMH is $34.15 / 1000$ births. The PNMR of Indra Rajya Laxmi Prasutigriha, Kathmandu is in the range of $40 / 1000$ births. ${ }^{9}$ The PNMR of Patan Hospital is $20.4 / 1000$ births, ${ }^{10}$ Tansen Mission Hospital is $91.2 / 1000$ births. ${ }^{11}$ Bheri Zonal Hospital is $138.8 / 1000$ births $^{12}$ and Tribhuvan University Teaching Hospital (TUTH), Maharajgung is $30.58 / 1000$ births. ${ }^{13}$
Our study shows that intranatal problems resulting still birth is $64.3 \%$ and post-natal problems causing early neonatal deaths is $35.7 \%$. Early neonatal death in our study is due to birth asphyxia (40\%), congenital abnormalities (20\%), sepsis $(20 \%)$, and severe prematurity $(20 \%)$.

Mostly, early neonatal deaths occurred in low birth weight babies (75\%). The baby who died due to septicemia was born full term, normally with vaginal delivery without any complications, but soon after delivery the baby developed septicemia, and died despite of treatment. Neonatal death due to severe prematurity with or without any complications could not be prevented. Effective and timely resuscitation of the asphyxiated babies would contribute in reducing early neonatal death. Neonatal death due to septicemia could be prevented by promoting exclusive breast-feeding and strict aseptic precaution while handling babies, and regular cleansing of the labour and neonate room. Good socioeconomic condition, education and nutritional condition of mother play a great role in reducing PNMR.

Fresh still birth due to intrapartum asphyxia could be easily reduced by better monitoring intrapartum and timely intervention for it. Still birth due to injury also can be prevented, if the mother came to hospital on time after the incidence. Due to late admission, stillbirth due to trauma could not be prevented. Still birth due to obstructed labour also can be reduced by better assessing the progress of labour and timely intervention. Still birth due to unknown causes could also be prevented, if the expecting mother came to hospital on time, soon after the feeling of loss of fetal movement.

\section{CONCLUSION :}

Although in our country, PNMR given by different sources are different, but data available from 
various hospitals confirm the high rate of PNMR.

The PNMR of Nepal as shown by division of Reproductive Health WHO 1997 AD is very high 75/ 1000 births and besides this, data available from various hospitals also confirm the high rate of PNMR. Perinatal Mortality is a big problem in our country in comparison to other developed countries.

In our study the causes of perinatal death is due to complications of labour. As shown above, the main causes of perinatal death are as follows: Severe prematurity with congenital abnormalities, trauma during pregnancy, fetal distress, obstructed labour, prolapsed fetal parts and low birth weight etc.

Perinatal mortality is a good parameter of the available health services of the country. Without reducing perinatal mortality it is not possible to reduce infant mortality as well as under five mortality rate. It also shows the socioeconomic and educational status of the people of our country.

In order to reduce PNMR and Under five mortality rate, it is very important to give attention on following points.

1. Health Education: As far as possible, heath education should be given to all expectant mothers on following topics;

i) Importance of nutrition during pregnancy.

ii) Hazards of too early and too late pregnancy.

iii) Hazards of smoking and drinking during pregnancy.

iv) Hazards of heavy manual work during pregnancy.

Besides this health education should be given about the importance of regular ANC visits.

2. Training: Training of different level of health worker. As most of deliveries are conducted by untrained birth attendants, praority should be given to them. All health workers involve in delivery conduction of the babies must be trained in the resuscitation of the new born baby.

3. Establishment of the referral centers for labour and delivery (Primary, secondary, tertiary level referral centers) according to the severity of risk factors. For those complications (of pregnancy and labour) which occur outside of hospital, improvement are desperately needed in the areas of community education, ANC, access to health care facilities.

4. Equipping the referral centers with appropriate equipment. The referral center should be posted with the health personnel trined in safe delivery procedure and resuscitation of new born baby.

5. Besides above recommendations, it is necessary to have good cooperation between peadiatrician and obstretician to provide quality services to the mothers and neonates. And the government should develop and implement such kind of national policy, which will help to reduce perinatal mortality.Besides these, health worker of all levels should work in such a style that help to reduce the present PNMR.

\section{ACKNOWLEDGMENT:}

We would like to thank Dr. Bharat Pradhan Director of Kathmandu Model Hospital for his kind permission to use hospital-data. Thanks are due to Ms. Maya Maharjan, Ms Bharati Bhetwal, Ms. Sabitri Dahal for their continuos help in analyzing data. We also like to thank Mr. Krishna Das Maharjan and Dr.Basant Maharjan for their help in preparing this paper. 


\section{REFERENCES:}

1. WHO, New born care, getting off to good start. Safe mother news letter.1996(2)-21:5.

2. WHO. Division of Reproductive Health. Maternal and Newborn Health /Safe Motherhood Unit 1997.

3. UNICEF, National Planning Commission H. M. G. Summary of the situation analysis on children and women of Nepal. Children and women of Nepal. A situation analysis 1992:1.

4. W.H.O. World HLTH STAT REP 29(4) 228. 1976.

5. The International Conference for the 9th $\mathrm{Re}$ vision of the International Classification of Disease 1978.

6. Synopsis of Pediatrics, 6th ed. Heights and Griffith.

7. Nelson's Text Book of Peadiatrics, 12th edition, 1983:322.

8. Meharban Singh, Development of Neonatal Services in Nepal, NEPAS Souvenir 1992, Vol.12(1):21-25.
9. Manandhar D.S, A Study of Perinatal Mortality at the Maternity Hospital, Kathmandu. Work Shop on Maternal and Perinatal Health and Family Planning 27-29 SEP. 1995:6067.

10. Adhikari Neelam, Perinatal Mortality A Hospital Based Study, Souvenir, NEPAS - Journal Vol.15, Issue I (Jan-June 1995):21-29.

11. Morgan C., Rongong R. and Maple-Brown L., Perinatal Mortality at United Mission Hospital, Tansen. JNMA Vol.36, No.123 JulySep.1997:320-323.

12. D. P. Pradhan, Usha Shah, Perinatal Mortality at Bheri Zonal Hospital, JNMA Vol.35, No.123 Jan.-March 1997:146-149.

13. Laxman Shrestha, Prof. Prakash S. Shrestha, Perinatal Mortality at Teaching Hospital T.U. Souvenir NEPAS 9th Nepalese Congress of Paediatrics, March 1998 Vol.18 Jan.-June:19-21.

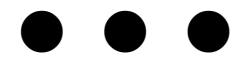

